\title{
EL TURISMO COMO FACTOR DE EXPLICACIÓN DE LOS DESEQUILIBRIOS TERRITORIALES: EL EJEMPLO DE LA ISLA DE LA GOMERA
}

\author{
Luis Manuel Jerez Darias* \\ Escuela Universitaria de Turismo Iriarte. Puerto de la Cruz (Tenerife) \\ https://orcid.org/0000-0002-8891-9817 \\ Víctor Onésimo Martín Martín** \\ Universidad de La Laguna \\ https://orcid.org/0000-0002-1551-8924
}

\section{RESUMEN}

La Gomera es una de las ocho Islas Canarias, un archipiélago considerado como uno de los destinos turísticos más importantes de Europa y del mundo. Su economía se desenvolvió históricamente a través de las actividades agrarias, pero a partir de los años ochenta del pasado siglo pasó a depender del sector terciario, siendo el turismo una base económica fundamental. El modelo turístico de La Gomera ha girado en torno al tradicional binomio de «sol y playa», favoreciendo su concentración en unos pocos espacios costeros del sur, lo que ha provocado una profunda polarización territorial -desde el punto de vista económico y demográfico- entre estas localidades y el resto de entidades de la isla. La consecuencia de ello ha sido el abandono casi total del territorio insular, el cual ahora se instrumentaliza como producto de promoción turística, apoyado en la idealización del paisaje como patrimonio natural y cultural, en la presentación del mismo como un espacio bucólico que seduzca y cautive a los visitantes alojados en la costa, principales consumidores de estos espacios del interior y norte insular, pero que poco aporta a la pobre economía de los habitantes que en ellos residen.

Palabras clave: La Gomera; polarización territorial; posproductivismo; paisaje; patrimonio territorial.

Fecha de recepción: 1 de septiembre de 2020

Fecha de aceptación: 20 de octubre de 2020.

* Escuela Universitaria de Turismo Iriarte. Paseo Santo Tomás s/n, 38400 Puerto de la Cruz TENERIFE (España). E-mail: luisjerez@iriarteuniversidad.es

** Departamento de Geografía e Historia. Universidad de La Laguna. Campus de Guajara s/n. 38200 La Laguna TENERIFE (España). E-mail: vbmartin@ull.edu.es 


\title{
Tourism as an explaining factor for territorial imbalances: The example of the island of La Gomera
}

\begin{abstract}
La Gomera is one of the eight Canary Islands, an archipelago considered one of the most important tourist destinations in Europe and the world. Its economy was historically developed through farming activities, but from the eighties decade of the past century, it became dependent on the service sector, with tourism being a fundamental economic basis. La Gomera's tourism model has revolved around the classic "sun and beach" combination, favoring its concentration in a few coastal areas in the south, which has led to a profound territorial polarization -from an economic and demographic point of view- between these places and the rest of the island. As a consequence, there has been an almost total abandonment of the island territory, which is now instrumentalized as a tourism promotion product, supported by the idealization of the landscape as a natural and cultural heritage, being presented as a bucolic space that seduces and captivates visitors staying on the coast, who are the main consumers of these interior and northern areas of the island, but which contributes little to the poor economy of the inhabitants residing in these areas.
\end{abstract}

Keywords: La Gomera; territorial polarization; postproductivism; landscape; territorial heritage.

\section{INTRODUCCIÓN}

La isla de La Gomera forma parte de las llamadas «islas menores» dentro del archipiélago canario, un calificativo que engloba varias connotaciones: reducido tamaño (370 $\mathrm{km}^{2}$ ), escasa población (21.678 en 2020), reducidos PIB y PIB per cápita (404 millones de euros y $18.785 €$ respectivamente, los segundos más bajos de la región, después de El Hierro), etc. Y desde el punto de vista turístico, pues, también. En nada se puede comparar a los valores que el turismo ofrece en islas como Tenerife, Gran Canaria, Lanzarote o Fuerteventura, donde dicha actividad ha generado una profunda transformación urbanística de determinadas localidades costeras. Esa distancia en las magnitudes turísticas que la separan de tales islas ha dado lugar a que también se le considere «isla verde», al igual que La Palma y El Hierro, donde el fenómeno turístico no ha dado paso a la masificación, presentando una serie de singularidades que en la actualidad se trata de utilizar como mecanismo de promoción turística, como son las características y grado de «conservación» de su paisaje y acervo cultural. Es la estrategia seguida por los organismos públicos locales desde hace algunos años para potenciar y distinguir el destino turístico de La Gomera, pero que, sin embargo, sigue manteniendo un desequilibrio territorial interno en cuanto a la distribución de las rentas derivadas de esta actividad entre los núcleos turísticos ubicados en el litoral meridional y el resto de localidades de la isla que, aún siendo utilizadas para esa promoción idealizada del paisaje y la cultura, no terminan de salir de su peculiar estado de precariedad social y económica. Esta es la casuística que pretendemos explicar en el presente trabajo, una primera aproximación a la resolución de una hipótesis 
que llevamos tiempo debatiendo: ¿el turismo, al igual que la agricultura de exportación, la industrialización o la urbanización, también crea desequilibrios territoriales? Pensamos que el presente articulo puede ayudar a resolver, en parte, esa pregunta y, por qué no, servir de modelo para otros estudios de similar problemática en otras áreas geográficas. Para ello, nos apoyamos en la consulta de diversas fuentes bibliográficas, de los distintos programas y planes de actuación aplicados en la isla en lo referente al turismo y estrategias de acción en el medio rural, y del trabajo de campo. Estas fuentes las consideramos como esenciales para articular un estudio de estas características en un espacio como La Gomera, una isla escasamente estudiada y para la que no existen determinados datos que sí están disponibles para otras.

\section{LAS ISLAS CANARIAS: UNA REGIÓN TURÍSTICA DE PRIMER NIVEL}

Las Islas Canarias conforman uno de los destinos turísticos más importantes del mundo. Su importancia como región turística radica, fundamentalmente, en su posición geográfica (cerca de Europa) y sus magníficos atractivos naturales, siendo el clima y sus costas los principales reclamos, si bien, en las últimas décadas se han integrado otros recursos naturales de alto valor paisajístico (generalmente integrados en la red de espacios naturales protegidos) y otros de carácter cultural (patrimonio etnográfico, arquitectónico, gastronomía, etc.) propios de las actuales tendencias postfordistas que han diversificado la oferta turística de las islas (Hernández Luis et ál, 2017: 364). Asimismo, otros aspectos a considerar son la seguridad del destino, tanto desde el punto de vista ambiental (ausencia de animales peligrosos, de enfermedades, temporales, etc.) como social (escasa delincuencia, terrorismo, etc.), y la moderación de los precios de consumo en casi todo el sector hostelero (alojamientos, restaurantes, bares, etc.) y comercial (moda, electrónica, souvenirs, etc.) en comparación a los lugares de origen (Morales Matos et al., 1999: 8; Marrero y Santana, 2008: 125-127). Reúne, por tanto, una serie de elementos que, en su conjunto, han convertido el archipiélago canario en un destino de primer nivel mundial.

\section{Mapa 1 \\ ISLAS CANARIAS}

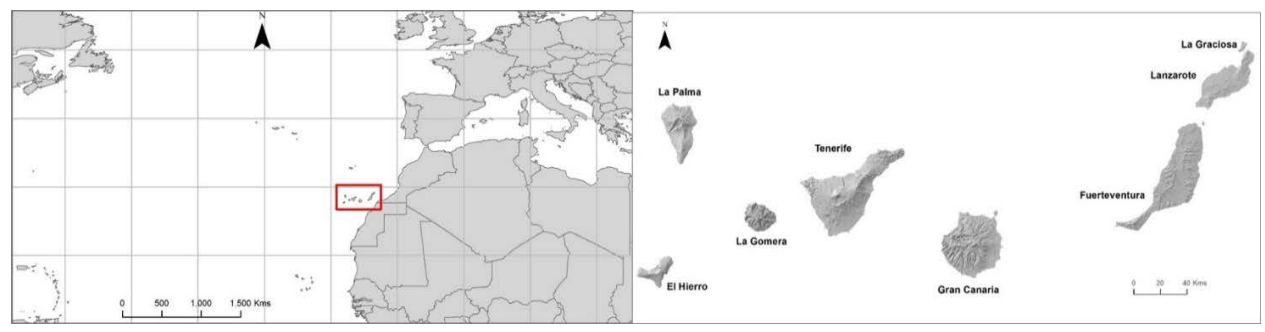

Fuente: Porto Tapiquén ${ }^{1}$, GRAFCAN. Elaboración propia.

1 https://tapiquen-sig.jimdofree.com/ 
Según los datos ofercidos por la Organización Mundial del Turismo para el año 2018, sólo 23 países $^{2}$ superaron el número de visitantes que recibieron las islas $(15.559 .787)^{3}$, un pequeño espacio archipielágico de tan sólo $7.447 \mathrm{~km}^{2}$ de superficie terrestre ${ }^{4}$. Así, destinos internacionales como Vietnam (15,5 millones), Indonesia $(13,4)$, Marruecos $(12,3)$, Egipto $(11,3)$, Irlanda $(10,9)$, Australia $(9,2)$, Túnez $(8,3)$, Argentina $(6,9)$ o Brasil $(6,6)$, entre otros, acogieron menos turistas que Canarias. Esto nos da una idea de la importancia cuantitativa del archipiélago como destino turístico en el contexto internacional. Y más protagonismo adquiere en el ámbito nacional. Según el Instituto Nacional de Estadística (INE), entre 2016 y 2020 Canarias ha alternado la segunda y tercera posición del ranking de las comunidades autónomas en número de turistas con Baleares 5 :

\section{Tabla 1}

NÚMERO DE TURISTAS EXTRANJEROS SEGÚN COMUNIDAD AUTÓNOMA

\begin{tabular}{|l|r|r|r|r|}
\hline \multicolumn{1}{|c|}{ CCAA } & \multicolumn{1}{c|}{$\mathbf{2 0 1 6}$} & \multicolumn{1}{c|}{$\mathbf{2 0 1 7}$} & \multicolumn{1}{c|}{$\mathbf{2 0 1 8}$} & \multicolumn{1}{c|}{$\mathbf{2 0 1 9}$} \\
\hline Cataluña & \multicolumn{1}{c|}{18.139 .177} & 19.118 .421 & 19.196 .344 & 19.358 .203 \\
\hline Baleares & 12.997 .549 & 13.792 .296 & 13.851 .598 & 13.680 .923 \\
\hline Canarias & 13.259 .567 & 14.214 .222 & 13.752 .022 & 13.147 .009 \\
\hline Andalucía & 10.589 .642 & 11.518 .262 & 11.681 .256 & 12.079 .017 \\
\hline Comunidad Valenciana & 7.731 .770 & 8.925 .959 & 9.206 .908 & 9.566 .566 \\
\hline Madrid (Comunidad de) & 5.783 .137 & 6.699 .785 & 7.139 .775 & 7.638 .375 \\
\hline País Vasco & 1.382 .083 & 1.514 .765 & 1.552 .389 & 1.631 .932 \\
\hline Galicia & 1.035 .147 & 1.291 .086 & 1.512 .511 & 1.634 .517 \\
\hline Castilla y León & 1.225 .331 & 1.458 .546 & 1.374 .464 & 1.309 .549 \\
\hline Murcia (Región de) & 924.305 & 991.209 & 1.134 .189 & 1.055 .610 \\
\hline Aragón & 644.516 & 562.352 & 545.530 & 549.753 \\
\hline Extremadura & 261.453 & 380.914 & 468.286 & 472.675 \\
\hline Cantabria & 378.435 & 414.489 & 381.181 & 414.089 \\
\hline Navarra (Comunidad Foral de) & 300.622 & 333.317 & 323.730 & 420.765 \\
\hline Asturias (Principado) & 277.989 & 294.129 & 299.357 & 329.689 \\
\hline Castilla La Mancha & 222.651 & 226.221 & 235.011 & 263.764 \\
\hline La Rioja & 150.779 & 124.189 & 142.926 & 141.889 \\
\hline Total & $\mathbf{7 5 . 3 1 5 . 0 0 8}$ & $\mathbf{8 1 . 8 6 8 . 5 2 2}$ & $\mathbf{8 2 . 8 0 8 . 4 1 3}$ & $\mathbf{8 3 . 7 0 1 . 0 1 1}$ \\
\hline
\end{tabular}

Fuente: INE. Elaboración propia.

2 Junto a estos países también se deben incluir las regiones administrativas especiales de Hong Kong y Macao, ambas pertenecientes a China. Fuente: OMT, Country profile - Inbound, Ranking of destination on key indicators, (https://www.unwto.org/country-profile-inbound-tourism).

3 ISTAC: FRONTUR-Canarias / Series mensuales de entradas de turistas y excursionistas. Islas de Canarias. 2012-2019.

4 Esta superficie es mayor si se incluye la marítima, tal y como se desprende de la Ley Orgánica 1/2018, de 5 de noviembre, de reforma del Estatuto de Autonomía de Canarias, art.4.2., pero de la que no hay datos oficiales. Según algunas fuentes (El Diario.es: https://www.eldiario.es/canariasahora/sociedad/Canarias-comunidadsuperficie-Estatuto-Autonomia_0_849015397.html), la superficie total del archipiélago sería de unos 36.500 km².

5 Si tomamos como referencia los datos que aporta el ISTAC para Canarias (FRONTUR), sus valores serían superiores a los de Baleares en esos años: $2016=14.981 .113 ; 2017=15.975 .507 ; 2018=15.559 .787 ; 2019$ $=15.110 .866$, lo que elevaría a la segunda posición permanente a Canarias. 
Esa importancia jerárquica se traduce, al mismo tiempo, en la enorme trascendencia que adquiere la actividad turística en la estructura económicade las islas. Analizando los resultados del Estudio IMPACTUR Canarias relativos al año 2018, se puede apreciar su enorme relevancia, pues el turismo aporta un PIB que supera los 16.000 millones de euros, lo que supone una contribución a la economía regional del 35\%. Y lo mismo ocurre en términos laborales, generando unos 344.000 puestos de trabajo, un 40,4\% del total del empleo de toda la comunidad autónoma (EXCELTUR, 2018: 5). La lectura negativa de esta alta dependencia de la economía isleña hacia el turismo lo evidencia la actual crisis provocada por la pandemia del COVID-19, adversidad que se suma a los efectos aún perdurables de la crisis de 2008, la quiebra del gigante turoperador británico Thomas Cook y las posibles consencuencias del Brexit para un destino donde el turismo británico es el principal, aportando más de 5 millones de turistas anuales ${ }^{6}$. Según un equipo de investigadores de la Universidad de La Laguna, hasta el 30 de abril de 2020 la economía canaria ya había perdido el $15 \%$ del PIB con respecto al mismo periodo de 2019 , lo que supuso que, en el primer cuatrimestre del año, el PIB de la región se redujese un 5\% (Díaz Hernández et al., 2020:17). En este mismo estudio, los autores planteaban tres posibles escenarios de repercusión de la crisis en el archipiélago para el año 2020 en comparación a 2019, dejando en evidencia el azote de la misma sobre su estructura económica y, especialmente, sobre el turismo.

\section{Tabla 2}

\section{IMPACTO DEL COVID-19 EN LA ECONOMÍA CANARIA}

\begin{tabular}{|c|c|c|c|c|}
\hline Escenarios & $\begin{array}{c}\text { Impacto sobre la } \\
\text { actividad turística }\end{array}$ & $\begin{array}{c}\text { Impacto sobre el } \\
\mathbf{N}^{\circ} \text { de turistas }\end{array}$ & $\begin{array}{c}\text { Impacto sobre el } \\
\text { PIB de Canarias }\end{array}$ & $\begin{array}{c}\text { Impacto sobre } \\
\text { el empleo } \\
\text { general }\end{array}$ \\
\hline Optimista & $-21 \%$ & $-60 \%$ & $-19 \%=-4.000(\mathrm{M} €)$ & $-20 \%$ \\
\hline Intermedio & $-19 \%$ & $-69 \%$ & $-21 \%=-4.700(\mathrm{M} €)$ & $-23 \%$ \\
\hline Pesimista & $-25 \%$ & $-73 \%$ & $-25 \%=-5.300(\mathrm{M} €)$ & $-27 \%$ \\
\hline
\end{tabular}

Fuente: Díaz Hernández et al., 2020:12-16. Elaboración propia.

La propia Consejería de Economía, Conocimiento y Empleo del Gobierno de Canarias, en su reciente informe de seguimiento del impacto económico del COVID-197, indicabapara el mes de marzo un fuerte descenso del PIB regional del $-6,6 \%$, un $-65 \%$ del turismo (960.000 viajeros menos) y del gasto turístico, y un descenso del $-11 \%$ en los afiliados a la hostelería y agencias de viajes. Son todos datos ilustrativos, aunque en lectura negativa, del peso del turismo en nuestra comunidad autónoma, una actividad que ha marcado el ritmo de su economía en las últimas cinco décadas.

6 Fuente: ISTAC. Entrada de pasajeros desde el extranjero según clases de tráfico por aeropuertos de destino, países de origen y periodos. Recopilación de Estadísticas de Transporte Aéreo / Series mensuales de entrada de pasajeros. Aeropuertos de Canarias. 1993-2020.

7 https://www.gobiernodecanarias.org/cmsweb/export/sites/economia/galeria/Galeria_politica_economica_2/Informe-de-seguimiento-impacto-covid-19_19-de-mayo-de-2020.pdf 
Canarias se insertó en el cicuito turístico internacional en la primera oleada de la década de 1960, dejando progresivamente atrás su pasado agrario. Desde entonces, la llegada de turistas no ha hecho más que crecer, salvo en determinadas coyunturas de crisis en las que se ralentizó la tendencia alcista, sobre todo, después de 2008 y en el momento actual.

\section{Gráfico 1 \\ EVOLUCIÓN DE LA LLEGADA DE TURISTAS A CANARIAS (1960-2019)8}

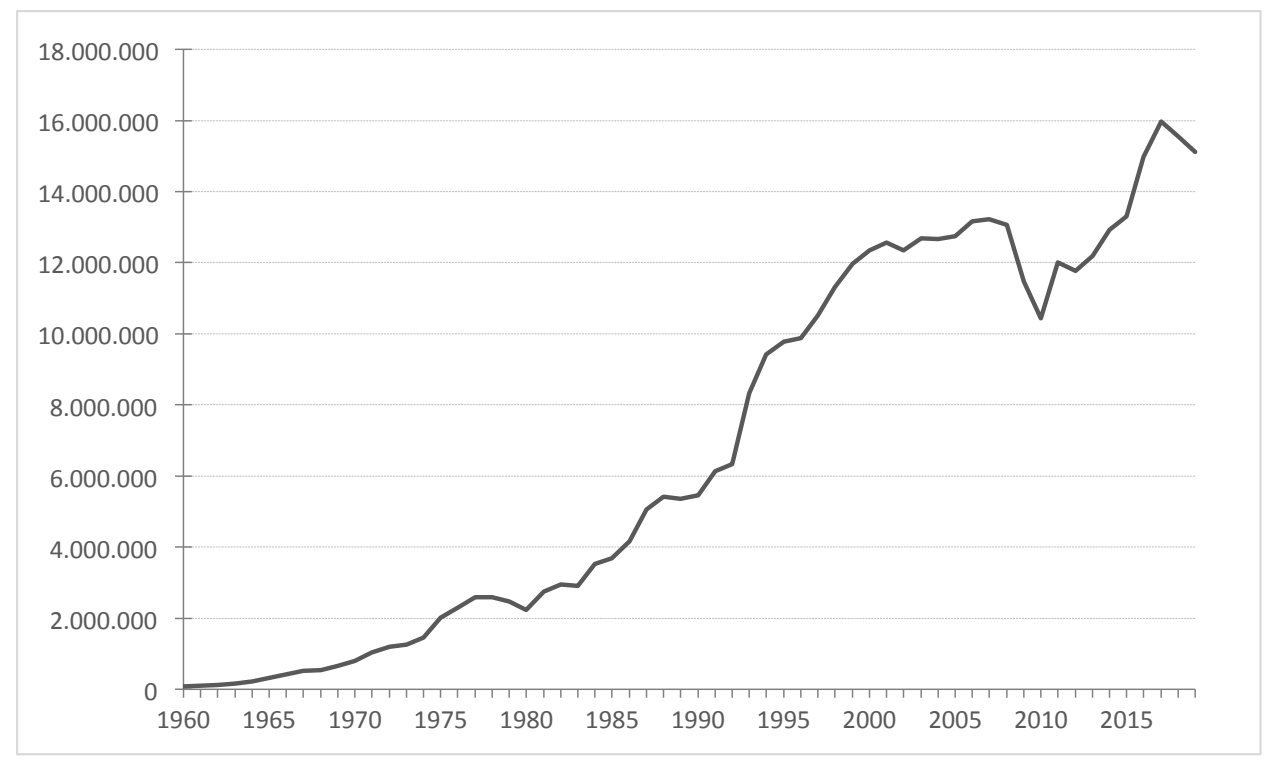

Fuente: Atlántida International Consultants; ISTAC. Elaboración propia.

El modelo turístico del archipiélago iniciado entonces se apoyó en su totalidad en el tradicional binomio de «sol y playa» hasta fechas recientes, el cual ha generado la transformación profunda de buena parte de los litorales de las islas de Tenerife, Gran Canaria, Fuerteventura y Lanzarote mediante un crecimiento urbanístico desmedido, sobre todo, en las costas meridionales. Se trató de un desarrollo urbanístico que no siempre estuvo propiciado por una mayor demanda alojativa, sino por mantener en funcionamiento dos actividades igualmente fundamentales en la economía isleña, a saber: la constructora y la inmobiliaria vinculadas, en este caso, al turismo (Martín Martín, 2000; García Márquez, 2007; Simancas Cruz, 2019; Domínguez Mújica, 2008).Pero, los azotes de las crisis, sobre todo la de 2008, y las nuevas tendencias de la demanda, han hecho que destinos turísticos maduros como Canarias tengan que ofertar nuevos productos para seguir siendo competitivos en el mercado internacional (flexibilización postfordista). En este sentido, no es de extrañar que el paisaje siga siendo uno de los pilares fundamentales de su oferta, sostenida

8 Los turistas aquí engloban tanto a los visitantes nacionales (peninsulares) como a los extranjeros. 
sobre la declaración y reconocimiento de una extensa red de espacios naturales protegidos (actualmente son 146) que representan el $40 \%$ de su territorio, entre los que existen cuatro parques nacionales que encumbran al archipiélago como la región con mayor número de esta categoría dentro de la red nacional. Además, cinco de las ocho islas se han declarado en su «integridad» Reservas Mundiales de la Biosfera por la UNESCO: Lanzarote (en 1993); El Hierro (en 2000); La Palma (en 2002); Fuerteventura (en 2009) y La Gomera (en 2012)(Hernández Luis, et al., 2017: 364). Como bien reconocen los autores, el amplio catálogo de protección ambiental al que se acogen numerosos espacios naturales de las islas ha sido un buen justificante para impulsar en ellas un turismo con características sostenibles. Y es en ese contexto, en el que islas como La Gomera o La Graciosa, entre otras, van abriéndose un hueco, si bien, funcionando como espacios complemetarios a las zonas de masificación de las islas turísticas adyacentes (Tenerife y Lanzarote respectivamente).

\section{LA GOMERA COMO DESTINO TURÍSTICO}

La Gomera es una de las ocho islas que conforman el archipiélago canario, región considerada como uno de los principales destinos turísticos de Europa debido a las magníficas condiciones geográficas que reúne (singularidad insular, clima, geomorfología, vegetación, etc.) (Morales Matos et al., 1999). Con tan sólo $370 \mathrm{~km}^{2}$ de superficie, es la tercera más pequeña del conjunto y forma parte del grupo de las islas occidentales. Hablamos, por tanto, de un territorio de pequeñas dimensiones, aunque mediano en cuanto a altitud, con el pico de Garajonay a 1.417 m.a. Ese carácter de montaña insular le permite albergar casi todos los tipos de formaciones vegetales que podemos encontrar en el archipiélago, a excepción del pinar y el de alta montaña, presumiendo, al mismo tiempo, de tener la muestra mejor conservada del monteverde, un ejemplo de formación relicta del Terciario. Otra de sus características es que tiene un relieve muy accidentado, con profundos barrancos y fuertes pendientes resultantes de una incesante y prolongada acción erosiva. Todo ello favorece una variedad de situaciones ecológicas y paisajísticas que han facilitado enormemente su desarrollo turístico.

La Gomera se divide en seis municipios. En la vertiente norte se localizan Agulo, Hermigua y una parte de Vallehermoso, pues la otra se despliega por la meridional, en la que también se sitúan los términos de Valle Gran Rey, Alajeró y San Sebastián, donde se ubica la capital. En estos últimos es donde se concentra actualmente la mayor parte de la población y dinámica económica (vinculada al turismo), mientas que los del norte han quedado estancados económica y demográficamente una vez que los servicios y el turismo entraron en escena a partir de la década de 1980, alterando por completo las bases de una estructura económica que hasta entonces se apoyaba fundamentalmente en la agricultura. 


\section{Mapa 2 \\ ISLA DE LA GOMERA}

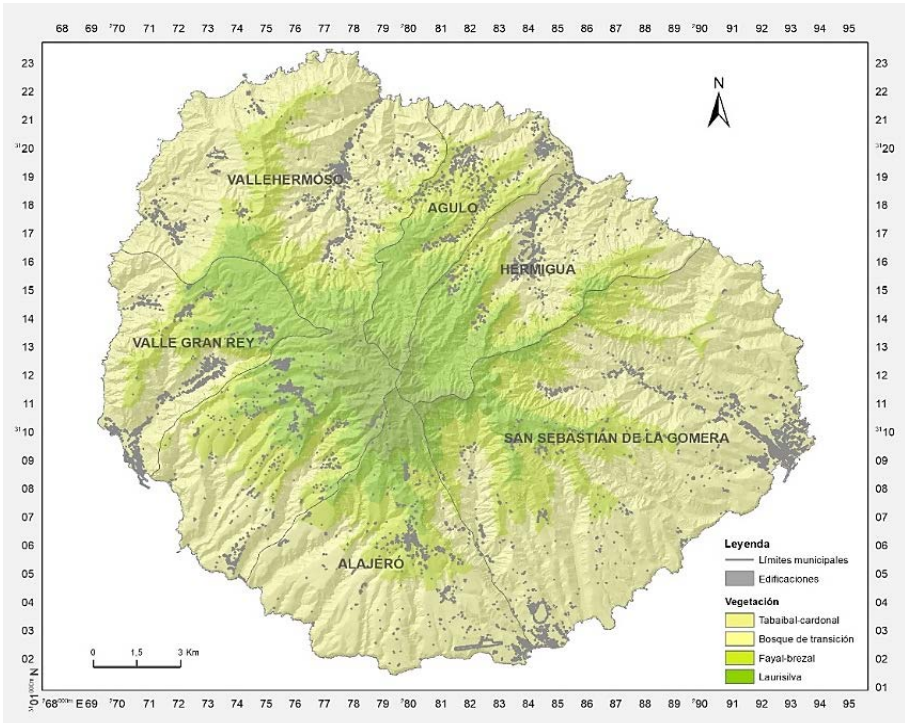

Fuente: Grafcan. Elaboración propia.

El modelo turístico de la isla, si bien bascula sobre el tradicional binomio de «sol y playa», difiere en algunos aspectos al implantado en las llamadas «islas turísticas» de Tenerife, Gran Canaria, Fuerteventura y Lanzarote (Hernández Luis, et al. 2017; Marrero y Santana, 2008). Éstas se caracterizan por su masificación, mientras que La Gomera, al igual que La Palma y El Hierro, soporta una presión turística mucho menor.

Otra de las singularidades de La Gomera es el tipo de turista que la visita. Por su cercanía a la isla de Tenerife (unos $30 \mathrm{~km}$ ) y de su principal centro turístico (costa suroeste), tiene la particularidad de recibir diariamente por vía marítima cientos de turistas procedentes de dicha zona, conformando lo que se conoce como «excursionistas» o «turistas de día», es decir, aquellos que visitan la isla por la mañana y regresan por la tarde al sur de Tenerife, por tanto, no pernoctan en ella. Es una categoría establecida por el Instituto Canario de Estadística (ISTAC) únicamente para La Gomera, para diferenciarla de los «turistas», que serían aquellos que sí pernoctan en la isla y que son los que se cuantifican para el resto del archipiélago 9 . Se trata de un flujo prácticamente inexistente en el resto de islas y de una magnitud considerable. Según los datos de 2018, el número de «excursionistas» en La Gomera fue de 299.141, frente a los 107.341 «turistas», una diferencia de 191.800 visitantes.Y esto ha determinado en gran medida el modelo turístico de la isla, pues la posiciona como un destino complementario a Tenerife, como una suerte de «parque temático» para los miles de turistas que se alojan en el sur de esta isla y que aportan muy poco a la economía gomera.

9 http://www.gobiernodecanarias.org/istac/galerias/documentos/E16028B/metodologia_FRONTUR.pdf 


\section{Gráfico 2 \\ NÚMERO DE TURISTAS POR ISLAS (2018)}

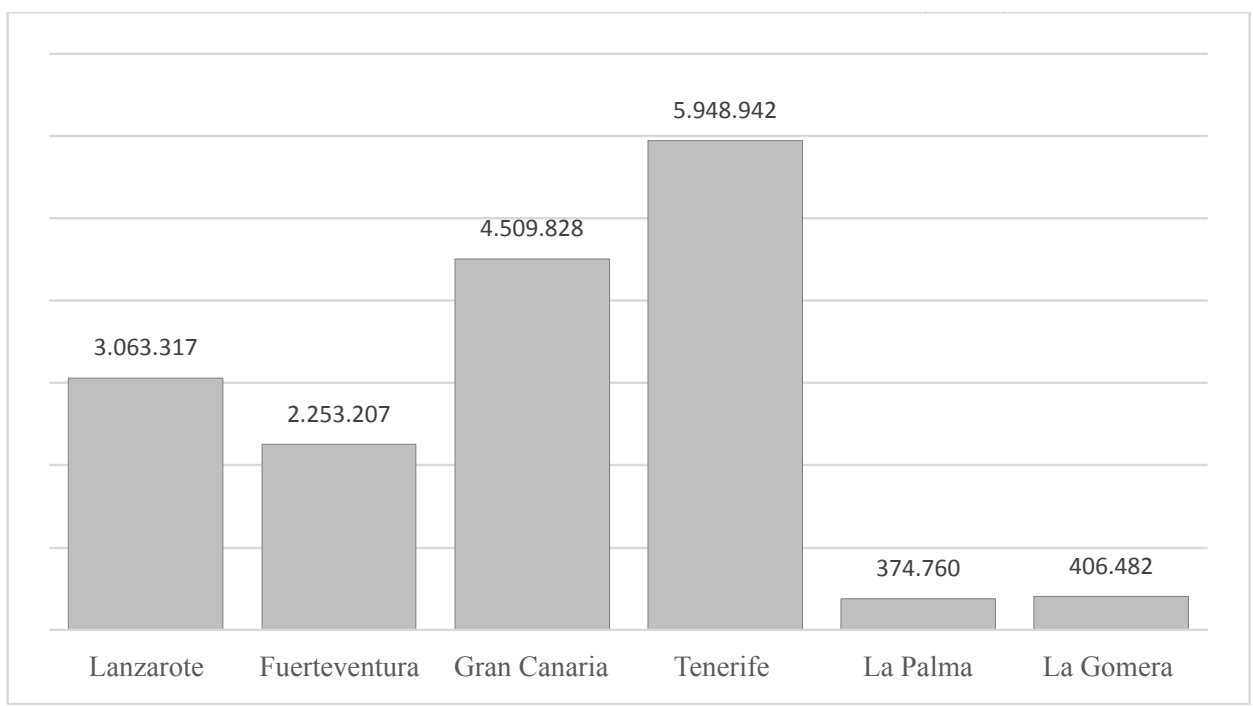

Fuente: ISTAC. Elaboración propia ${ }^{10}$.

\section{EL DESARROLLO DEL TURISMO EN LA GOMERA: ABANDONO DEL CAMPO Y POLARIZACIÓN TERRITORIAL}

Evitando remontarnos a momentos pretéritos para tratar de buscar los inicios del turismo en La Gomera, tarea que escapa a los objetivos de este artículo, creemos que es a partir de la década de 1980 cuando podemos marcar el periodo de implantación del turismo como una actividad significativa dentro de la estructura económica insular. Hasta entonces, y partiendo desde el periodo de conquista iniciado a mediados del siglo XV, la economía gomera había basculado alrededor de la agricultura, la cual se basaba en dos modelos de explotación: el de subsistencia y el de exportación. Este último tipo de agricultura estuvo controlado por los grandes propietarios de la tierra, quienes se ligaron a los agentes foráneos que operaban en las islas desde principios del siglo XX, principalmente británicos y noruegos, para desplegar estos cultivos en sus tierras. Y sería sobre los predios de estos potentados situados en la costa meridional donde posteriormente se desarrollarían los complejos turísticos más importantes de la isla, proceso contrario a lo que acaecía en los núcleos del interior y del norte insular, donde la crisis del sistema agrario tradicional expulsó a una importante masa de población. Se abría, de este modo, un nuevo escenario de polarización territorial en la isla que perdura en la actualidad, con unos centros económicos vinculados a las actividades terciarias -jalonadas por el turismo- localizados en la

10 Para la isla de La Gomera se incluyen tanto los «turistas» como los «excursionistas». Para El Hierro y La Graciosa no existen datos disponibles después de 2015. 
costa meridional, frente a unos espacios completamente estancados, tanto desde el punto de vista económico como social y demográfico, en el resto insular.

\subsection{La crisis agraria y sus repercusiones socioterritoriales}

Como apuntamos anteriormente, la mayor parte del territorio insular estuvo definido históricamente por la actividad agrícola. Desde el periodo de conquista (iniciado a mediados del siglo XV) hasta la década de 1980, el espacio insular fue transformado intensamente para ser cultivado. Pero, a partir del decenio de 1960, esta actividad comenzó a decaer. En el proceso que se iniciara en España en la segunda mitad de los años 50 (Ley del Suelo de 1956 y Plan de Estabilización de 1959), La Gomera tuvo la misma participación que aquellos espacios de economía más atrasada, a saber: como una zona de expulsión de la fuerza de trabajo. Primero Venezuela, y luego el sur y el ámbito Santa Cruz-La Laguna en Tenerife, fueron los focos de acogida de la cuantiosa emigración gomera.

\section{Gráfico 3 \\ EVOLUCIÓN DE LA POBLACIÓN DE LA GOMERA. 1900-2018}

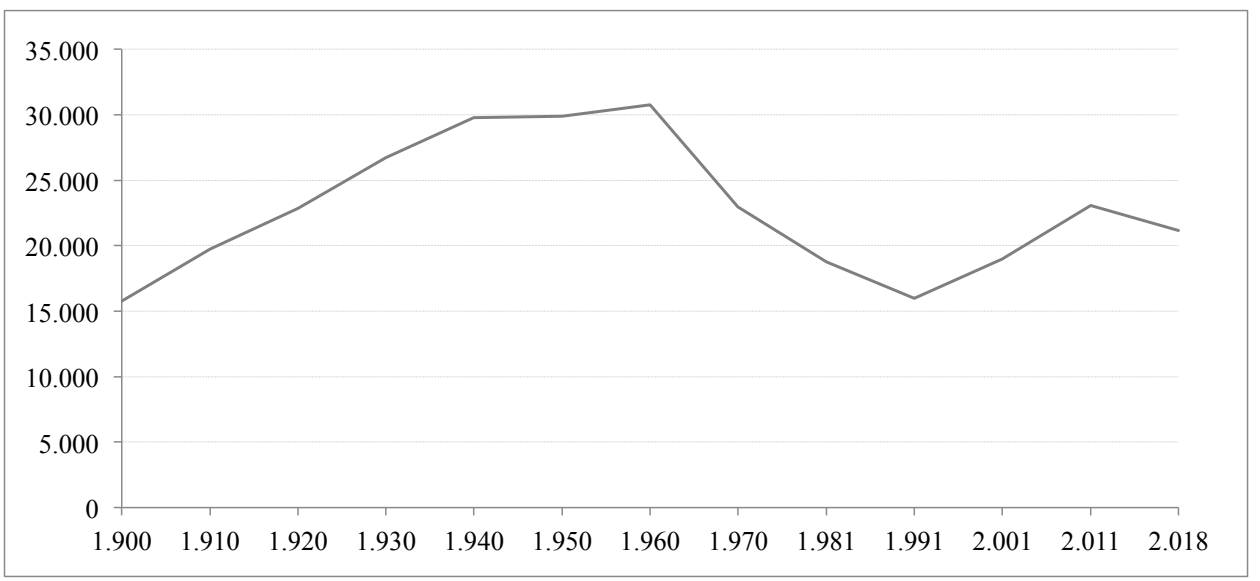

Fuente: INE. Censos de población. Elaboración propia.

Al mismo tiempo, en el seno de la isla aconteció un proceso de polarización territorial dirigido hacia la hegemonía económica, política y demográfica de los municipios de la vertiente meridional, principalmente de San Sebastián, donde se localiza la capital de la isla. Ese cambio de orden fue la expresión local de lo ocurrido en la base económica nacional, con el reemplazo de las actividades primarias por las secundarias y terciarias a partir de la década de los 60. En La Gomera este proceso se dejó sentir, primero, con los movimientos emigratorios y, más tarde, con la terciarización y desarrollo inmobiliario y turístico. 
La cara opuesta de este proceso quedó reflejada en la crisis secuencial del agro insular, sometido a un abandono constante, sobre todo, en las zonas del norte y de medianías ${ }^{11}$.

\section{Gráfico 4 \\ EVOLUCIÓN DE LA POBLACIÓN POR MUNICIPIOS. 1900-2018}

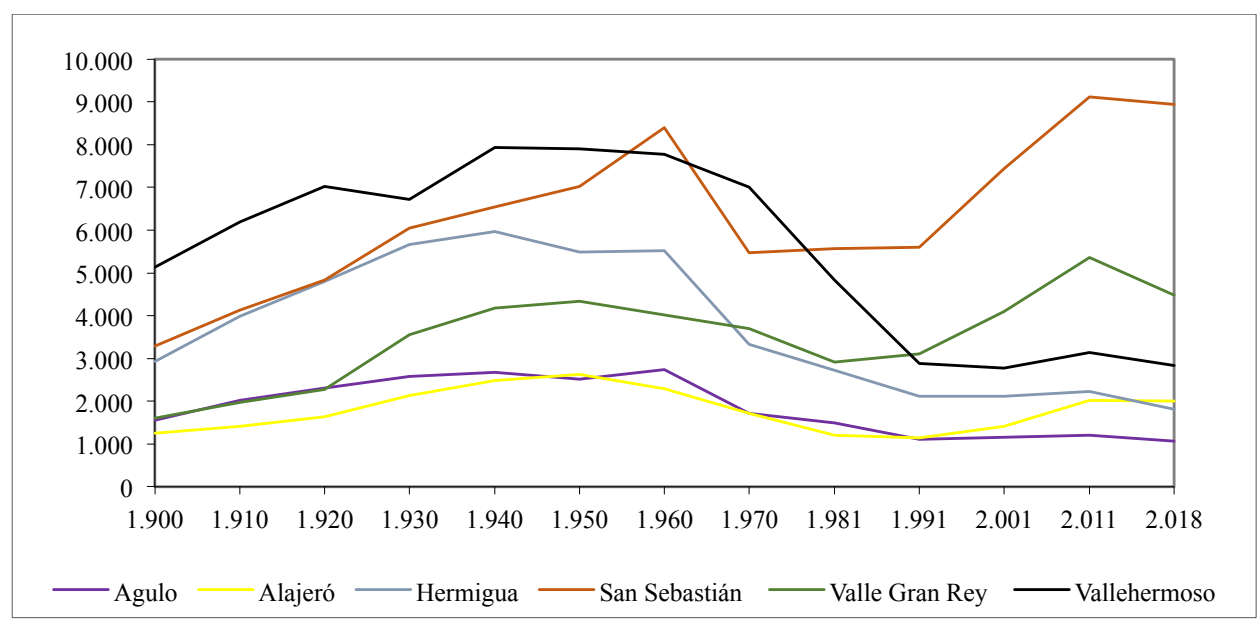

Fuente: INE. Censos de población. Elaboración propia.

Los valles de Hermigua y Vallehermoso, además de Agulo, habían sido históricamente los lugares que presumían de un estatus económico y social más distinguido en La Gomera. En sus cabeceras municipales residían algunas de las familias más notables de la sociedad insular. Los sucesivos monocultivos de exportación habían otorgado a estos pueblos un papel preponderante que fueron perdiendo a partir de la segunda mitad del siglo $\mathrm{XX}$, una vez que la actividad comercial-exportadora pasó a concentrarse en el puerto de San Sebastián. Además, a esto debemos añadir la consolidación de los ámbitos de Valle Gran Rey y, sobre todo, de Playa de Santiago, donde la agricultura de exportación y la pesca en manos de potentes agentes foráneos atrajo numerosa mano de obra a la zona. Se produjo entonces una modificación de la estructura económica insular que, en tan sólo dos décadas, reorganizó por completo el orden geoeconómico que había imperado en la isla durante cinco siglos. Y la aparición del turismo tuvo mucho que ver en ello, pues fue una actividad fundamental en el proceso de terciarización económica insular y de impulso del sector de la construcción concentrada en las localidades meridionales. Se daba, por tanto, un golpe definitivo al modelo tradicional propio de los ámbitos agrarios de las medianías y del norte insular, los cuales han quedado sumidos en una profunda crisis que perdura

11 En Canarias las medianías identifican a la franja situada entre los 500-900 metros de altitud, donde tradicionalmente se desarrolló el policultivo gracias a la humedad aportada por vientos alisios que afectan a las islas. En todo caso, ese intervalo varía en función de la vertiente en la que nos encontremos. Así, en la de barlovento la zonificación podría establecerse entre los 400-900 m.a., y en la de sotavento entre los 600-1.000 m.a. La mayor parte es de secano. 
en la actualidad. Todo lo contrario, ocurrió en las entidades del sur, donde se siguen concentrando las principales infraestructuras (aeropuerto, puertos comerciales y deportivos, sanitarios, etc.) y desarrollos turísticos de la isla.

\section{Gráfico 5 \\ EVOLUCIÓN DE LA POBLACIÓN SEGÚN VERTIENTES. 1900-2018}

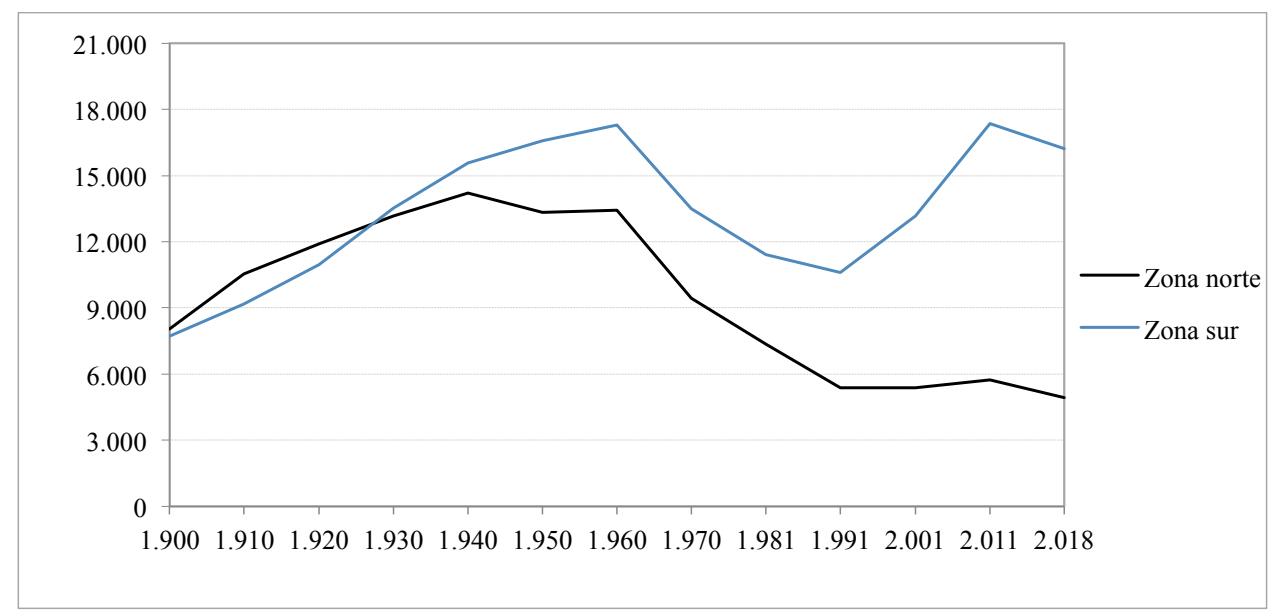

Fuente: INE. Censos de población. Elaboración propia.

\subsection{La consolidación de los centros turísticos en el litoral meridional}

Sin poder afirmar con rotundidad el lugar de mayor penetración del fenómeno turístico en la isla, consideramos que fueron San Sebastián y Valle Gran Rey los ámbitos pioneros del desarrollo del turismo en La Gomera, proceso al que se incorporaría algo más tarde la localidad sureña de Playa de Santiago.

Hasta finales de los años 60 y principios de los 70, la actividad turística en la isla se había reducido a visitas esporádicas e individuales de algún viajero que, en su tránsito por el archipiélago, recalaba en ella. Pero, sería al calor de la expansión que se estaba generando en la vecina Tenerife cuando La Gomera comenzó a recibir más visitantes, derivando en el desarrollo de las primeras iniciativas turístico-alojativas de interés.

El municipio de San Sebastián, por su función capitalina y portuaria, actuó históricamente como la puerta de entrada a la isla, por tanto, como el principal lugar de tránsito y estancia de visitantes en la misma, rol que adquirió mayor protagonismo a partir de mediados de la década de 1950, cuando comenzó a operar el puerto (Darias Príncipe y Díaz Padilla, 1994). La coyuntura abierta con la puesta en marcha de la nueva infraestructura y la previsible importancia que adquiría la actividad turística -que ya fijaba raíces en otras islas del archipiélago-, llevó al ayuntamiento capitalino a formular la idea de la construcción de complejos turísticos en la localidad, propósito que se materializó entre finales de 
los años 60 y principios de los 70 con la construcción y apertura del Parador Nacional de Turismo Conde de La Gomera, una de las instalaciones más importantes en la actualidad.

Posteriormente, con la puesta en marcha de la línea marítima regular que unía La Gomera con Tenerife a través de un ferry (a mediados de los años 70), la actividad turística tomó un notable impulso, de forma que empezaron a sucederse diferentes propuestas para la construcción de desarrollos turísticos en el municipio, aunque no fue hasta la segunda mitad de los años 80 cuando se construyó el Hotel Jardín Tecina en la localidad sureña de Playa de Santiago (territorio repartido entre los municipios de San Sebastián y Alajeró). Este complejo de 4 estrellas fue ejecutado por la empresa Fred Olsen S.A., sociedad titular del ferry citado y la mayor propietaria de la isla, e interesada en abandonar su faceta agroexportadora para destinar sus terrenos al uso turístico. Esa estrategia se ha prolongado hasta la actualidad mediante el desarrollo de nuevas ampliaciones del hotel, la construcción de un campo de golf y nuevos complejos residenciales como el Pueblo de Don Thomas (Jerez Darias, 2012).La construcción del Hotel Jardín Tecina en esta localidad fue el punto de partida de la especialización turística de la zona. A esa iniciativa -y ampliaciones posteriores- le siguieron la construcción del Hotel Santa Ana (en el sector de Alajeró) y las edificaciones de apartamentos llevadas a cabo por pequeños empresarios y particulares de la localidad.

Junto a estos complejos, en el municipio también funciona el pequeño hotel situado en la Playa de El Cabrito, el más singular de todos los que existen en la isla por su carácter agroecológico, y las dos urbanizaciones aún en construcción de Lomo del Clavo y Bahía de Avalos situados al nordeste de la capital. En su conjunto, toda esta oferta alojativa ha convertido a San Sebastián en el municipio que contiene las mayores urbanizaciones turísticas, si bien, la mayor parte de las plazas se concentran en el término de Valle Gran Rey.

Valle Gran Rey también fue el otro municipio pionero en el turismo de «sol y playa» en la isla a finales de la década de 1960. Adelantándose a lo ocurrido en Playa de Santiago, algunas de las primeras influencias del turismo alojativo en la isla podemos situarlas aquí. Las colonias de alemanes que buscaban destinos alternativos a la predecible masificación y estandarización turística del sur de Tenerife o de Gran Canaria, encontraron en Valle Gran Rey un idílico lugar para pasar sus vacaciones, e incluso, para fijar una residencia. Se rompía de esta manera en el municipio el binomio tradicional «agricultura-pesca» para dar paso al sector servicios. Así, en los años 70 Valle Gran Rey experimentó un crecimiento demográfico al calor de la incipiente actividad turística que fue capaz de brotar en estos parajes(ver Gráfico 4), lo que motivó la redacción de varios planes de ordenación urbanística con los que tratar de dirigir el proceso urbano-turístico del municipio. Hablamos del proyecto de Plan General aprobado en 1971 y del plan parcial Zona del Litoral de Valle Gran Rey de 1973, los cuales no tuvieron mucha incidencia a la hora de regular la realidad urbano-turística que pretendían ordenar. Valle Gran Rey se sumaba a la tónica habitual del planeamiento elaborado en esta etapa, esto es, la desconexión entre el ideario planificador (urbanista) y una realidad socioeconómica y cultural no acostumbrada a tales medidas. El resultado fue la proliferación de pequeños alojamientos de carácter familiar diseminados por el valle, una solución que supuso la reconversión de los antiguos campesinos en «empresarios» turísticos (Jerez Darias, 2017: 153-154). En todo caso, en Valle Gran Rey también sería la década de 1990 la que abría el paso a las construcciones de 
nuevo tipo, a las urbanizaciones turísticas de mayor envergadura, aunque sin llegar a las dimensiones de las planteadas en San Sebastián. En la actualidad, si bien Valle Gran Rey sigue siendo un destino caracterizado por su componente hippie y «mochilero», no es menos cierto que la proliferación de esos complejos de apartamentos y hoteles ha seguido su curso, lo que indica la consolidación del municipio dentro de los circuitos turísticos estandarizados de sol y playa.

\subsection{La distribución geográfica de la planta alojativa: la evidencia de la polarización territorial}

Desde la perspectiva del turismo, si de algún modo ha quedado patente el desequilibrio territorial es en la distribución espacial de la planta alojativa. Como en el resto de las islas del archipiélago y de los destinos de sol y playa, la mayoría de los alojamientos turísticos en La Gomera se concentra en la costa; situación contraria a la del interior, donde sólo aparece una reducida oferta vinculada fundamentalmente al turismo rural, de carácter disperso y muchas veces complementaria de aquella.

Atendiendo a los datos aportados por el Cabildo Insular de La Gomera y de nuestro propio trabajo de campo, hemos cuantificado 403 alojamientos ${ }^{12}$ que se dividen en dos categorías: la planta hotelera y la extrahotelera ${ }^{13}$. Dentro de la primera modalidad se encuentran los hoteles y hoteles rurales, mientras que, en la segunda, los apartamentos y las casas rurales, a los que acompaña la ambigua y polémica figura -todavía a día de hoy- de las viviendas turísticas (viviendas vacacionales).

Partiendo de esa clasificación, cabe decir que la oferta turístico-alojativa en La Gomera es pequeña pero variada, lo que revela que es un sector que se ha ido adaptando a diferentes demandas a pesar de estar dominada por los apartamentos y las viviendas turísticas. Ambos alojamientos suponen casi la mitad de la oferta total de La Gomera y se concentran mayoritariamente en la franja costera meridional (donde representa el 92\% de la planta), al igual que los hoteles.

A nuestro entender, tal predominio tiene una base histórica, ya que fueron los prototipos que se implantaron en los inicios del desarrollo turístico de la isla. La Gomera, alejada de los circuitos masivos con grandes inversiones en complejos hoteleros propias de islas como Tenerife o Gran Canaria, se basó en la iniciativa familiar. Ésta se caracterizó por la construcción de pequeños alojamientos o grupo de apartamentos anexos a las viviendas de los propietarios, tendencia que ha perdurado hasta nuestros días. Y en el medio rural se actúa a través de las pequeñas casas rurales, que es la tipología más numerosa en esta zona, denotando un proceder muy atomizado de la actividad alojativa a pesar de su reciente implantación.

12 Hay que puntualizar que esta cantidad no es la real, pues sólo mostramos una parte de la planta legalizada debido a la desactualización de las fuentes. Por tal motivo, hemos realizado un trabajo de campo, el cual, por otra parte, no lo cubre todo, dada la complejidad del mismo. Además, debemos tener en cuenta la oferta ilegal existente en la isla, de la que no existen datos oficiales.

13 Decreto 142/2010, de 4 de octubre, por el que se aprueba el Reglamento de la Actividad Turística de Alojamiento y se modifica el Decreto 10/2001, de 22 de enero, por el que se regulan los estándares turísticos. 
Las casas rurales es un producto prácticamente nuevo en La Gomera, siguiendo, con un poco de retraso, la estela de lo ocurrido en otras islas (Parreño, 2008; García et al., 2000). Su presencia parte de principios del nuevo milenio, cobrando paulatinamente mayor protagonismo conforme se ha ido consolidando esta nueva tendencia turística. A diferencia de periodos anteriores, en la actualidad, la concepción ambientalista ha ido penetrando con rapidez en el sector turístico, permitiendo la revalorización y puesta en marcha de zonas que anteriormente quedaban al margen de dicha actividad (Cánoves, et al., 2005). Es por ello, que los municipios de Agulo, Hermigua o Vallehermoso, ajenos al modelo tradicional de sol y playa, se hayan integrado en el sector a través de la variante rural.

En menor cuantía aparecen los hoteles, sobre todo los rurales, lo que pone en evidencia que la infraestructura alojativa de La Gomera responde mayoritariamente a unidades de pequeñas dimensiones, representadas por las viviendas turísticas y las casas rurales, a las que habría que añadir la mayoría de los apartamentos y de los hoteles. Sólo en estas dos últimas categorías aparecen complejos de gran tamaño que, unidos a unas pocas promociones de mediano-alto standing, denotan un elevado nivel de las inversiones realizadas y alejadas de las iniciativas familiares y de pequeña empresa dominantes en el resto. Y esto se percibe, fundamentalmente en el caso de los hoteles, en el número de plazas (camas) que ofrece.

\section{Gráfico 6 \\ NÚMERO DE ALOJAMIENTOS TURÍSTICOS SEGÚN TIPOLOGÍA EN LA GOMERA}

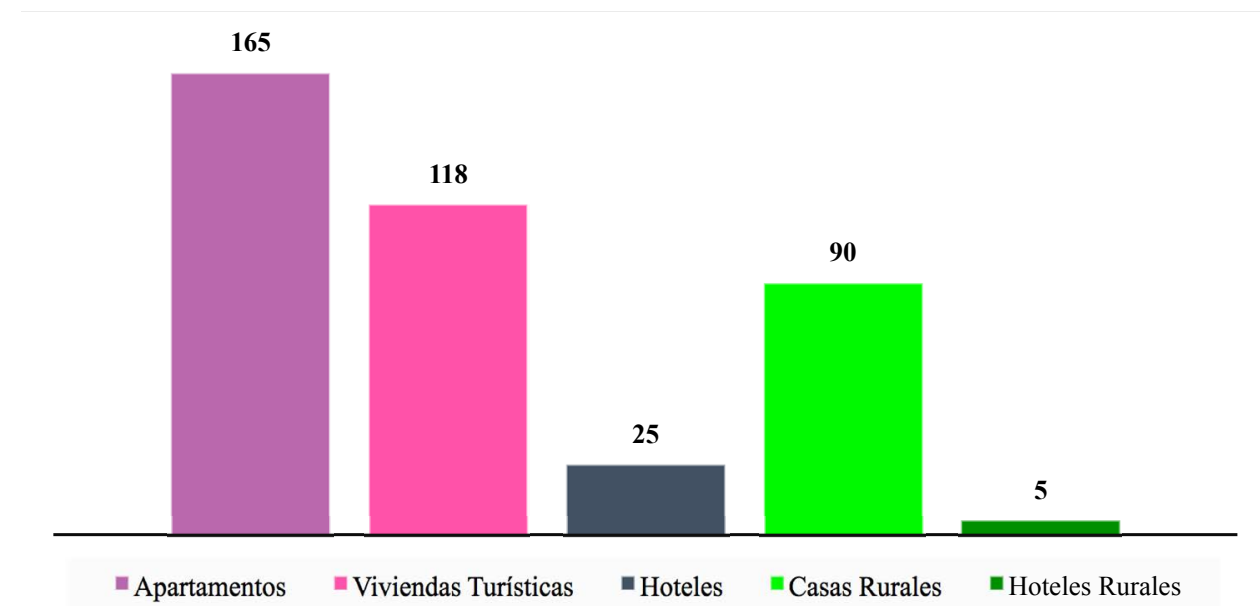

Fuente: Cabildo Insular de La Gomera. Elaboración propia. 


\section{Gráfico 7 \\ NÚMERO DE PLAZAS SEGÚN TIPOLOGÍA ALOJATIVA}

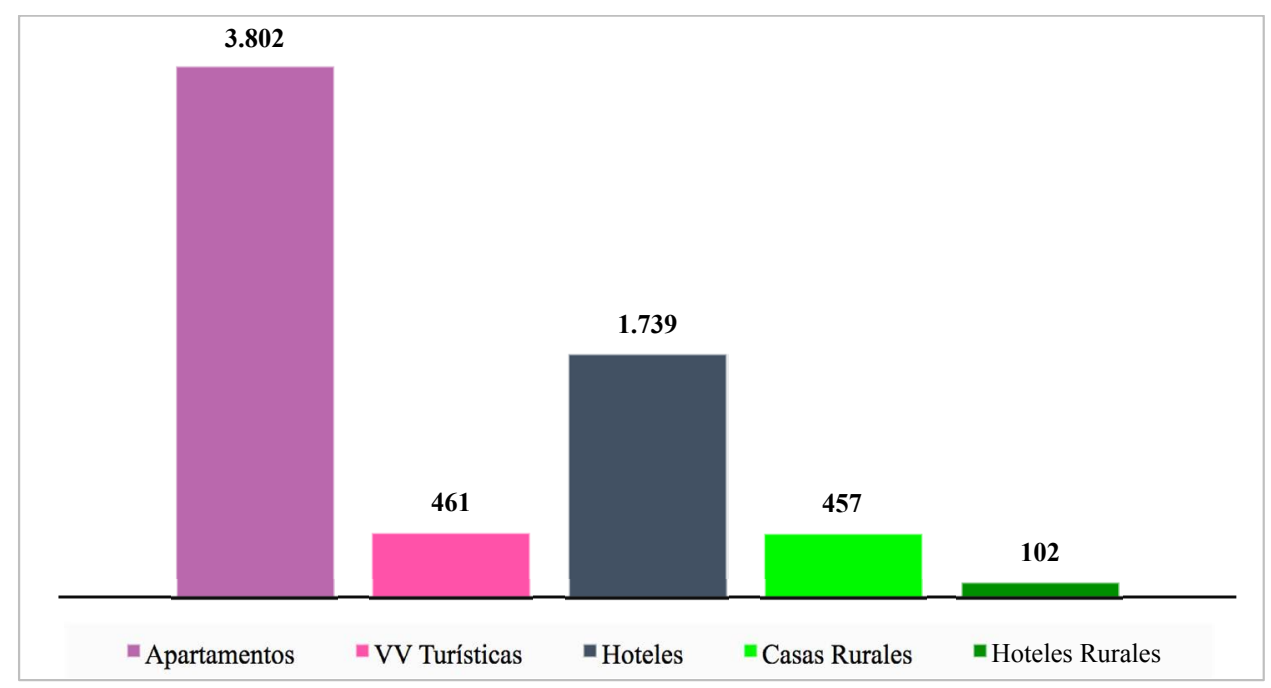

Fuente: Cabildo Insular de La Gomera. Elaboración propia.

Pero, como apuntamos anteriormente, esa variada oferta alojativa no se encuentra repartida equilibradamente por el territorio insular, la mayor parte de la misma se concentra en las mencionadas localidades sureñas de San Sebastián, Playa de Santiago y Valle Gran Rey. Es el resultado de la dinámica del modelo de sol y playa imperante en la isla. En estos puntos es donde se emplazan los hoteles, los apartamentos y las viviendas turísticas, las cuales suponen casi la totalidad de la oferta alojativa de La Gomera, todo lo contrario, a lo perceptible en los valles del norte y zonas del interior insular, donde las tipologías se reducen a las variantes de turismo rural (hoteles y casas).

Como se puede apreciar en el mapa, casi toda la oferta alojativa de los municipios del sur se concentra en la costa. En cambio, su territorio interior se mantiene como un espacio secundario, a pesar de que en los últimos años se haya implantado cierta infraestructura alojativa de turismo rural. Por su parte, en los municipios del norte la dinámica es otra. En ellos la distribución de los alojamientos se presenta más diseminada. Aquí no podemos hablar de verdaderos núcleos turísticos al modo que los hacemos para el sur. Su infraestructura tampoco responde a grandes complejos hoteleros o de apartamentos, sino a pequeñas unidades alojativas de turismo rural. Son, fundamentalmente, las antiguas viviendas de los campesinos o hacendados reformadas y acondicionadas para esta actividad las que se distribuyen por los principales valles y barrancos de la vertiente septentrional. El caso de Agulo es representativo en este sentido: el $91 \%$ de su oferta está compuesta por las casas rurales, la mayor de la isla para esta categoría. Le siguen en orden Hermigua (70\%) y Vallehermoso $(47 \%)$. 


\section{Mapa 3 \\ DISTRIBUCIÓN GEOGRÁFICA DE LOS ALOJAMIENTOSTURÍSTICOS SEGÚN TIPOLOGÍA}

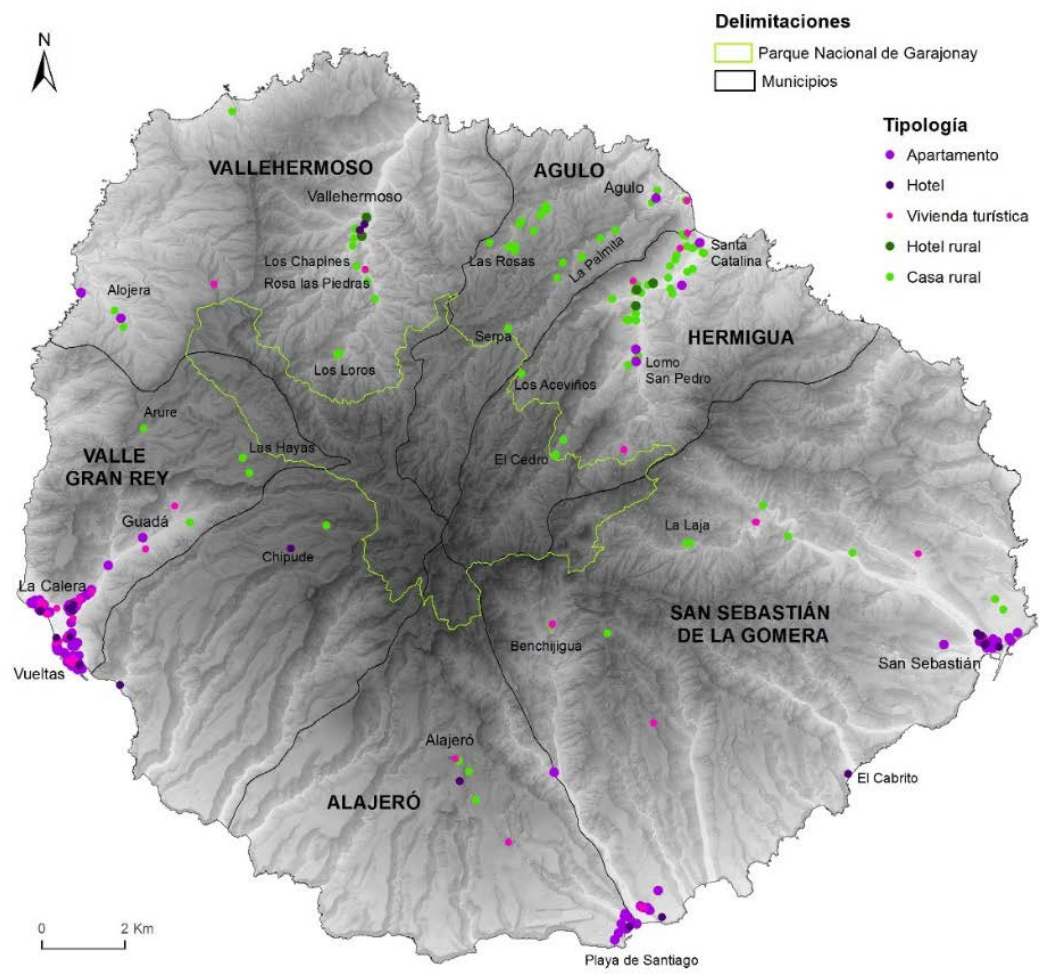

Fuente: Cabildo Insular de La Gomera. Elaboración propia.

\section{NÚMERO DE ALOJAMIENTOS TURÍSTICOS Y PLAZAS POR MUNICIPIO}

\begin{tabular}{l|cc|rr}
\hline Municipio & $\mathrm{N}^{\circ}$ Alojam. & \% Alojam. & \multicolumn{2}{c}{$\mathrm{N}^{\circ}$ Plazas } \\
Agulo & 23 & $5,7 \%$ & 124 & $1,9 \%$ \\
Alajeró & 24 & $6,0 \%$ & 685 & $10,4 \%$ \\
Hermigua & 45 & $11,2 \%$ & 330 & $5,0 \%$ \\
San Sebastián & 52 & $12,9 \%$ & 1.789 & $27,3 \%$ \\
Valle Gran Rey & 229 & $56,8 \%$ & 3.389 & $51,7 \%$ \\
Vallehermoso & 30 & $7,4 \%$ & 244 & $3,7 \%$ \\
\hline Total & 403 & $100,0 \%$ & 6.561 & $100,0 \%$ \\
\hline
\end{tabular}

Fuente: Cabildo Insular de La Gomera. Elaboración propia. 
En términos generales, el número de alojamientos por municipio no es muy elevado, y tampoco presenta muchas disparidades entre ellos, a excepción de Valle Gran Rey, que concentra algo más de la mitad del total insular $(56,8 \%)$. Similar lectura debemos hacer sobre el número de plazas, con un incremento importante en el caso de San Sebastián debido a que es el municipio donde se localizan los complejos turísticos de mayor envergadura y ejecutados por empresas foráneas como, por ejemplo, el Hotel Jardín Tecina, de capital noruego. Algo parecido ocurre en el término de Alajeró, donde también existe un complejo de apartamentos denominado El Balcón de Santa Ana, el cual tiene más de 334 plazas, es decir, más de la mitad de las camas del municipio, y desarrollado por una empresa inglesa. Estos datos son indicadores que marcan la diferencia del modelo turístico de la costa meridional con respecto al norte e interior, donde la actividad turístico-alojativa es muy escasa dentro del ámbito insular, tanto en número de alojamientos como de plazas. Sólo entre San Sebastián y Valle Gran Rey se concentra el 70\% de los alojamientos y el 79\% de las plazas de la isla; y si a éstos sumamos los datos de Alajeró, el porcentaje asciende al $76 \%$ y $89 \%$ respectivamente. Este grado de concentración de la oferta alojativa en esos tres municipios meridionales es el claro indicador de la polarización socioeconómica que viene padeciendo La Gomera desde hace varias décadas, un desequilibrio que sentó sus bases en la etapa agraria con la irrupción de los grandes propietarios foráneos que trastocaron el tradicional orden geoeconómico insular y que en la actualidad se ha vigorizado al calor de la actividad turística.

\section{LA PATRIMONIALIZACIÓN DEL PAISAJE: POSTPRODUCTIVISMO Y RECREACIÓN TURÍSTICA}

La masificación y saturación del modelo tradicional de sol y playa ha provocado en las últimas décadas una reorientación de la actividad turística a nivel global, en la que se incorporan una serie de actividades más respetuosas con el medio ambiente y la cultura de los destinos. Variantes como el turismo rural, el ecoturismo, el turismo cultural, deportivo, etc., son ahora modalidades que explotan nuevos nichos de mercado (Vera et al., 1997; Martínez Quintana, 2017). Esta realidad también se ha materializado en La Gomera, aunque, en cierta medida, no es algo tan novedoso como en las principales islas turísticas de Canarias, donde el peso del sol y la playa ha sido más evidente. En este sentido, el turismo que afluye a La Gomera tiene ciertas particularidades. En primer lugar, siempre ha dominado el turismo alemán ${ }^{14}$, más proclive a combinar el disfrute de la costa con los entornos naturales y rurales del interior y que poco tiene que ver con el británico instalado en los destinos costeros estandarizados de las otras islas; y, en segundo lugar, por la alta presencia de los «excursionistas» que, en su ruta diaria por la isla, consumen la mayor parte de la jornada transitando por las zonas del interior. Lo que sí ha ocurrido desde comienzos del nuevo siglo es una reafirmación de este modelo, perceptible en el crecimiento de la planta alojativa rural y a la expansión de un turismo de naturaleza ampliamente apoyado y fomentado desde los organismos públicos locales.

14 Por tomar la referencia más actualizada, en 2019 representaron el 45,2\%, siguiéndoles de lejos los procedentes del Reino Unido con un 20,3\%. (Fuente: Promotur. Informe Perfil del turista. La Gomera. 2019, p. 3. https://turismodeislascanarias.com/sites/default/files/promotur_la_gomera_2019.pdf). 


\subsection{El paisaje gomero: la piedra angular de su modelo turístico}

Hablar del paisaje de La Gomera es hablar de su pasado agrario y de su riqueza natural, dos elementos estrechamente imbricados. La importancia del primero, de lo que consideramos el paisaje cultural derivado de las actividades agrarias, radica en la enorme capacidad de transformación territorial a la que sometió tales actividades al primigenio entorno natural durante varios siglos. Desde las tierras altas hasta la costa, la actividad agrícola y ganadera se extendieron dejando escasos espacios intactos, pues, hasta el propio bosque que hoy conforma el Parque Nacional de Garajonay sufrió sus acometidas. Por tanto, el paisaje y el medio rural gomero debemos asociarlo a la totalidad insular, independientemente de que esa funcionalidad tradicional haya quedado actualmente reducida a unos pocos ámbitos.

\section{MAPA 4 \\ ESPACIO CULTIVADO EN 2018}

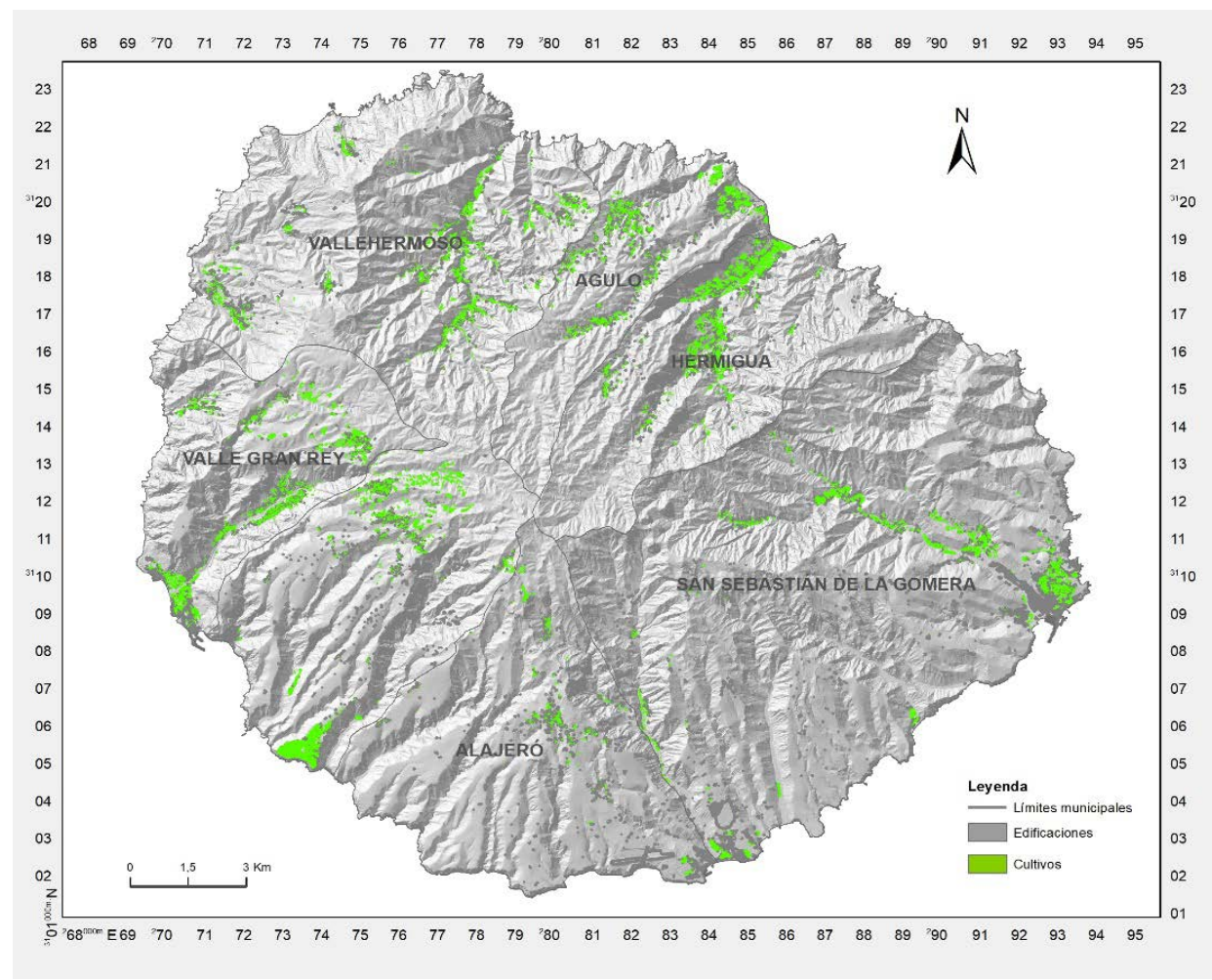

Fuente: Grafcan y Consejería de Agricultura, Ganadería, Pesca y Aguas del Gobierno de Canarias. Elaboración propia. 
Muchos vestigios de tales actividades humanas persisten actualmente sobre el territorio evocando un proceso secular de aprovechamiento del medio ya superado. El ejemplo más representativo lo constituye el impresionante sistema de bancales que el campesinado gomero construyó con fatigoso trabajo para obtener espacios horizontales de cultivo en las inclinadas laderas. Asimismo, otras muchas señales de ese pasado agrario han desaparecido o se encuentran en ese proceso como, por ejemplo, los antiguos caseríos abandonados, las infraestructuras hidráulicas, los pajares y establos, las eras, etc. De todo ese mosaico de reliquias pretéritas son muy pocas sobre las que la sociedad actual influye para revitalizarlas. Sólo los antiguos caminos que comunicaban las diferentes localidades y algunas viviendas tradicionales gozan de una atención por su atractivo turístico. El resto se ha ido desvaneciendo con el tiempo.

\section{Imagen 1 \\ PAISAJES RURALES ABANDONADOS}
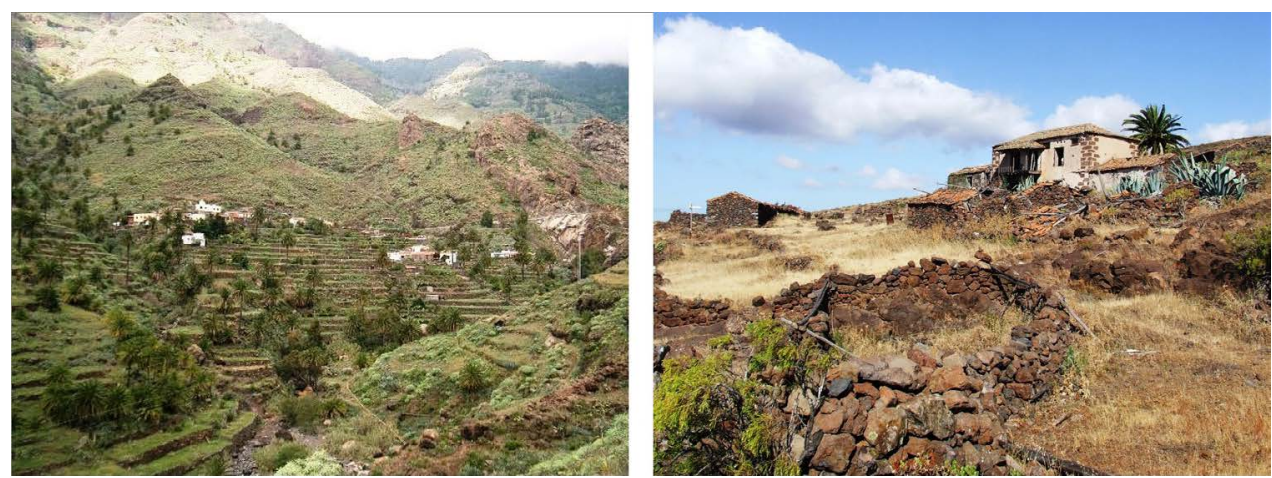

Fuente: Elaboración propia.

Por su parte, la importancia del entorno natural se fundamenta en una riqueza geomorfológica, florística y faunística de primer orden que puede valorarse actualmente a través de la extensa red de espacios naturales protegidos que posee: 17 en total que suponen el $33 \%$ del territorio insular( $\left.123.15 \mathrm{~km}^{2}\right)$. Se trata de una protección que, a nuestro parecer, cumple con dos funciones. Por un lado, adelanta una protección frente a posibles escenarios de transformación irreversible del medio geográfico derivada de procesos urbanísticos. Pero, por otra parte, no es menos cierto que la declaración de estos espacios protegidos favorece una distinción del destino turístico de La Gomera. Sus valores paisajísticos, su patrimonio territorial -ya de por sí destacado- bajo una categoría de protección es un potente reclamo para el mercado turístico, más aún, en el contexto actual de expansión de las nuevas modalidades de turismo alternativo o posfordista (ecoturismo, turismo activo, turismo rural, etc.). Y esto es un hecho que se constata en la realidad con la afluencia diaria de todo tipo de visitantes. Atendiendo a los datos de Promotur 2019, los atractivos naturales y las actividades que se practican en ellos son los factores más valorados por los turistas que visitan la isla, superando ampliamente la valoración hecha 
para el resto de Canarias en casos como el «entorno ambiental» $\mathrm{o}$ «explorar o conocer las islas» (49\% frente al $33 \%$ y $41 \%$ frente $18 \%$ respectivamente $)^{15}$.

\section{Mapa 5 \\ ESPACIOS NATURALES PROTEGIDOS}

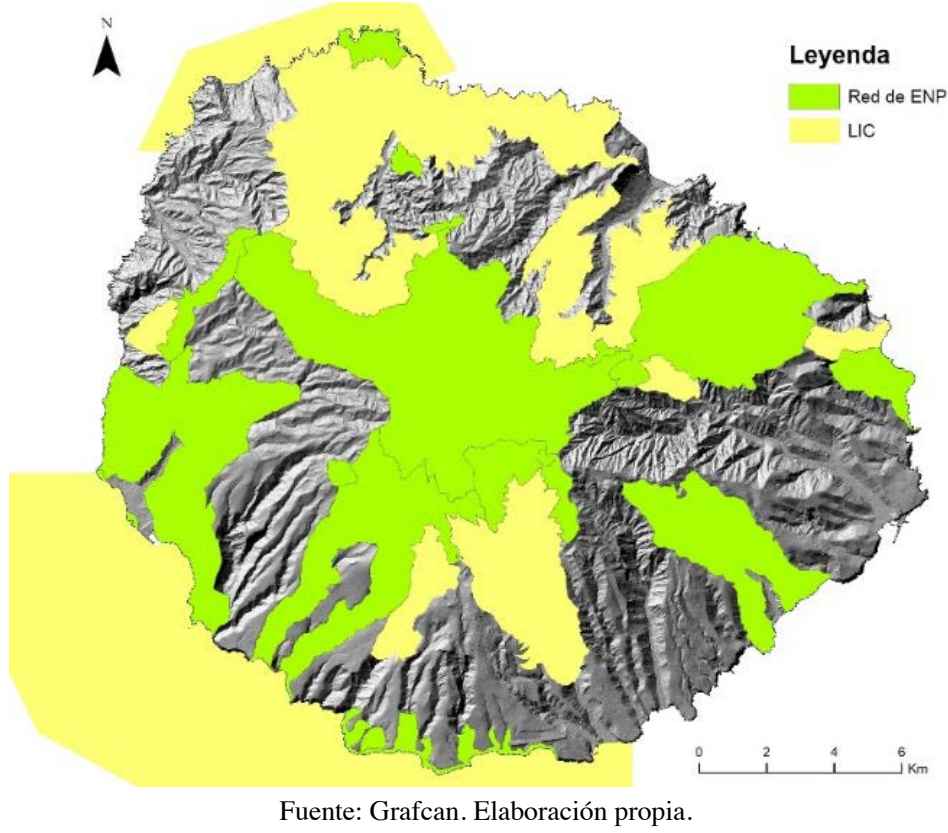

De ese modo, el paisaje insular -integrado por su medio natural y cultural- es el punto de gravedad sobre el que bascula la actividad turística en La Gomera. Los antiguos caseríos rurales, el formidable sistema de bancales o terrazas de cultivos (muchos abandonados y en ruinas), sus parajes naturales (protegidos o no) y su extensa red de caminos (hoy destinados a la práctica del senderismo) forman parte de la oferta actual del «qué ver»o «qué visitar» en La Gomera. Frente a la ausencia de otro tipo de ofertas de ocio, cultura, etc. que puede brindar la isla, su paisaje es el principal reclamo desde el punto de vista turístico. Este paisaje se ha convertido en una suerte de patrimonio territorial del que son inseparables los elementos naturales de los antrópicos, pues no se puede entender el territorio gomero obviando la profunda transformación de la que ha sido objeto por parte de la sociedad isleña a lo largo de varios siglos.

15 Promotur. Informe Perfil del turista. La Gomera. 2019, p. 1. (https://turismodeislascanarias.com/sites/ default/files/promotur_la_gomera_2019.pdf). 


\subsection{La desagrarización del medio rural: postproductivismo y contemplación turís- tica}

Ya apuntamos anteriormente que la mayor parte del territorio insular está conformada por el medio rural, un espacio que fue ampliamente transformado por las actividades agrarias, principalmente por la agricultura, y que actualmente se ha reorientado hacia una función meramente contemplativa, en el que las tradicionales actividades económicas y estilos de vida asociados han dado paso a un nuevo escenario postproductivista dependiente de las subvenciones públicas para incentivar el turismo. Teniendo en cuenta las evidentes particularidades del ámbito de estudio, se trata de un fenómeno generalizado a nivel mundial reconocido bajo el concepto de «desagrarización», el cual se presenta en La Gomera como un apéndice al proceso de crisis y despoblamiento del campo insular iniciado en los años 60 de la pasada centuria.

\section{Gráfico 8 \\ EVOLUCIÓN DE LA SUPERFICIE CULTIVADA (HAS.). 2000-2018}

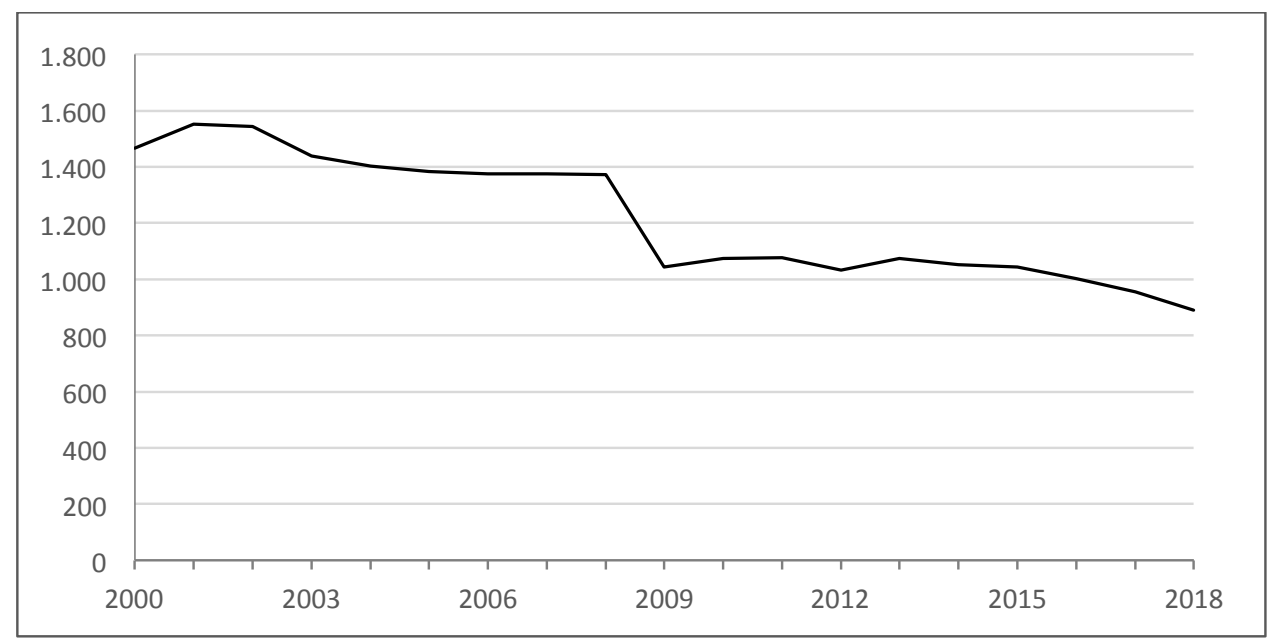

Fuente: ISTAC. Elaboración propia.

Como puede verse en el gráfico 8 , la actividad agrícola en la isla sigue mantiendo la tendencia de descenso iniciada décadas atrás ${ }^{16}$, marcando una diferencia de más de 600 hectáreas en 18 años; un claro indicador del abandono de la agricultura. Y si la agricultura retrocede, ¿qué está ocurriendo en las zonas rurales de La Gomera? Pues, básicamente, un estancamiento absoluto desde el punto de vista socioeconómico. Ante la ausencia de algún atisbo de desarrollo económico, la emigración y el alto grado de envejecimiento de la población siguen siendo una constante en estos lugares, pues, como vimos en el Gráfico 3, la población de los municipios rurales (Agulo, Hermigua y Vallehermoso) no ha parado

16 Según los datos extraídos del Catastro de Rústica de 1957, la superficie cultivada en ese momento era de unas 2.200 hectáreas (Jerez Darias, 2017: 103,107). 
de descender, a la que habría que añadir la de las zonas rurales de los municipios turísticos (San Sebastián, Alajeró y Valle Gran Rey), en las que el número de habitantes también ha disminuido en favor de sus localidades costeras. Es la continuidad de la polarización socioeconómica de la que hablamos anteriormente y que parece no tener fin. Ante esto, lo que se plantea desde las administraciones locales para revertir esta dramática situación es la apuesta por el turismo vinculado a la naturaleza y las actividades desarrolladas en el medio rural. Un medio rural que ahora se ofrece como imagen bucólicca de su pasado productivo y al que se destinan ingentes cantidades de dinero público, no para su puesta en producción, sino para mantener su paisaje como recurso turístico, planteando una especie de «musealización» de los mismos para el deleite y disfrute de los turistas alojados mayoritariamente en la costa.

Lo que hasta hace pocos años carecía de valor, por su abandono y escasa rentabilidad, con la irrupción del turismo rural y el ecoturismo ha ido adquiriendo importancia como producto turístico. Las nuevas lógicas que definen el turismo en la actualidad están convirtiendo los espacios rurales en un mero recurso turístico. En este sentido, el proceso de terciarización ha tomado aquí su propio matiz, pues, frente al estandarizado desarrollo de la urbanización en las cabeceras municipales y centros costeros, el abandono de estos espacios agrarios ha dado paso a la conservación. Desatendida la faceta productiva del medio rural, ahora se trata de insertarlo en el nuevo concierto económico como un bien de consumo turístico, como un patrimonio territorial reducido a sus valores paisajísticos y patrimoniales (Segrelles, 2001: 44; Millán, 2002: 224). Se trata de una tendencia surgida en las sociedades postindustriales en lo referente al mundo rural y valores medioambientales, y que ha supuesto una reorientación funcional del mismo (Molinero, 2003; Rubio, 2010). Este es el ideario definido por la Unión Europea desde la Declaración de Cork en 1996, recogido también en documentos como la Estrategia Territorial Europea (ETE) de 1999, y que va en la línea de fomentar la diversificación de la economía en aquellos espacios en crisis como son las zonas rurales. Por tanto, las estrategias encaminadas a conseguir esos fines deben orientarse hacia una regeneración que relacione las actividades primarias, las terciarias y la protección medioambiental y cultural, pues las zonas rurales se las considera una prioridad para la UE (González, 2001:37). A esto ha contribuido enormemente, por un lado, la declaración de los espacios naturales protegidos, y por otro, las iniciativas comunitarias, principalmente la LEADER.

En el marco de la política europea orientada al desarrollo de las zonas rurales, el turismo es uno de los vectores fundamentales para materializar sus objetivos, y con mayor profusión en territorios como el canario, considerados por la Unión como «regiones Objetivo 1», es decir, las más atrasadas según la política regional europea. Bajo esta óptica, se establece que el turismo constituye un instrumento importante para el desarrollo, la diversificación económica y la creación de empleo en el mundo rural (Millán, 2002: 226).

En La Gomera, el programa LEADER II (aprobado en 1994) es el que ha proporcionado mayores fondos, centrándose, fundamentalmente, en el desarrollo del turismo rural y en la conservación y mejora del medio ambiente insular (Febles, 2003: 284). Esta aportación ha facilitado la rehabilitación de numerosas viviendas tradicionales que han sido destinadas por sus propietarios, principalmente urbanos, a alojamientos rurales, concentrados mayoritariamente en los municipios norteños (ver Mapa 3). Pero, para el caso 
que nos ocupa, esa plurifuncionalidad del medio rural se desvanece en favor del turismo. Si bien esta actividad puede ser un canal esencial para la diversificación económica de estos espacios, en La Gomera parece presentarse como el único. Y esto puede comprobarse rápidamente analizando la planificación diseñada para los mismos.

\subsection{Las iniciativas diseñadas: la conservación paisajística como fundamento}

Junto a la declaración de los espacios naturales protegidos, en la isla se han desarrollado variadas líneas de actuación orientadas a promover un tipo de turismo basado en el fomento de los valores paisajísticos (naturales y culturales) como recurso turístico. En primer lugar, cabe mencionar la elaboración de una planificación territorial que se han ido «adaptando» a los nuevos contextos abiertos en la actividad turística. A pesar de que ninguna de las distintas figuras de planificación haya dejado de incidir en la concentración de la misma en el litoral meridional, con el paso del tiempo han ido integrando otros espacios que anteriormente escapaban a una proyección turística como son los espacios rurales.

El apresurado desarrollo turístico que conoció el archipiélago canario en las últimas décadas, con su intensa presión sobre el territorio y medio ambiente, derivó en la formulación de una normativa y planificación bastante densa y compleja. Todo ello bajo el pretexto de formular estrategias de regulación y la planificación de la actividad turística con criterios de sostenibilidad (García Márquez, 2007; Hernández Luis et al., 2017: 375). Bajo el paraguas de las Directrices de Ordenación General y del Turismo de Canarias aprobadas en 2003 se inició en La Gomera una planificación insular para el turismo. Primero se desarrolló el Plan Territorial Especial del Desarrollo Turístico de La Gomera, aprobado en 2003. Este documento se insertaba en el marco de la ley 6/2002, de 12 de junio, sobre medidas de ordenación territorial de la actividad turística en las islas de El Hierro, La Gomera y La Palma; una ley ad hoc para estas islas que facilitaba la urbanización turística en el medio rural, y que, como veremos, sería retomada posteriormente. Dicha ley reivindicaba para las llamadas «islas verdes», entre otros objetivos, permitir un modelo turístico alternativo al de sol y playa, sustentado en la puesta en valor del paisaje como recurso, al tiempo que establecer mecanismos que facilitasen el traslado al mundo rural de inversiones turísticas para el mantenimiento, conservación y mejora del paisaje. Y esas directrices las asumió rápidamente el citado plan territorial especial:

«Sin embargo es necesario, entender y valorar la importancia de estas pequeñas explotaciones..., y que están contribuyendo en la actualidad a mantener e incluso recuperar parte de un paisaje rural y agrario que es sin duda constitutivo de una gran parte de la riqueza cultural y paisajística intrínseca de La Gomera, y que sin duda atraen una parte importante del turismo actual y cuyo desarrollo y crecimiento depende del mantenimiento de estos paisajes» (Memoria, pp. 207).

El testigo del plan territorial lo tomó posteriormente el Plan Insular de Ordenación de La Gomera, aprobado en 2011, en el que se definía al turismo como la única actividad capaz de transformar la realidad socioeconómica gomera y, concretamente, de sus zonas rurales. La crisis económica surgida en 2008 dejó paralizadas las expectativas turísticas ideadas, pero, 
en la actualidad, la insistencia por buscar salidas al desarrollo económico de los espacios rurales de la isla se ha visto nuevamente favorecido por la reciente aprobación de la Ley 14/2019, de 25 de abril, de ordenación territorial de la actividad turística en las islas de El Hierro, La Gomera y La Palma; que no es más que una actualización de la aprobada en 2002.

Por otra parte, junto a esa planificación territorial han aparecido otros elementos de notable interés que intentan hacer de La Gomera un destino «sostenible». Ante la imposibilidad de las islas «menores» como la nuestra de competir con las llamadas «islas turísticas», se les hace perentorio diseñar modelos «alternativos» para insertarse en el contexto actual de las nuevas demandas turísticas. Para el caso que nos ocupa, la declaración de La Gomera como Reserva de la Biosfera en el año 2012 por la UNESCO (en la categoría de «excelente») ha contribuido enormemente a este hecho, sin olvidarnos de la Carta Europea de Turismo Sostenible aprobada en 2008. Este último documento, que se plantea para todo el ámbito insular, tiene como objetivo global promover el desarrollo del turismo en clave de sostenibilidad en los espacios naturales protegidos de la isla, incluyendo también iniciativas orientadas a conseguir la diversificación del medio rural. Podríamos considerar la Carta como la apuesta más exigente en lo referente al turismo en La Gomera, pero la dependencia que tiene de diversos agentes (privados y públicos) -muchas veces con intereses contrapuestos- para ser aplicada, ha provocado que buena parte de las iniciativas diseñadas hayan quedado en saco roto, situación que no favorece lo más mínimo a salir de la situación de parálisis en las que se encuentran sumidas las zonas rurales de la isla. En este sentido, debemos tener en cuenta que la mayor parte de los «consumidores» de estos espacios son los «excursionistas» que visitan diariamente la isla, y éstos no aportan muchos beneficios a la economía local, tal y como recoge el trabajo de Escuela (2016) sobre la modalidad del turismo de jeep safari en la isla. Según este estudio, esta tipología turística supone el 30\% de los «excursionistas» (casi 90.000 visitantes en 2018), de los que un 70\% gastan entre 0-10 euros, y sólo el $10 \%$ más de 40 euros, digamos, poco dinero (Escuela,2016: 4, 20). Por tanto, si esta modalidad tiene ese nivel de gasto, ¿podríamos pensar que el $70 \%$ restante de los «excursionistas» realiza mayores desembolsos? No se dispone de datos oficiales al respecto, pero todo nos hace pensar que no. Y prueba de ello es la escasa oferta de hostelería y comercio que existe en estas zonas, centrada en unos pocos establecimientos en las cabeceras municipales, únicos lugares con cierto dinamismo más allá de la capital insular y núcleos turísticos meridionales. Es decir, que la mayor parte del territorio insular sólo se define como un lienzo paisajístico para el disfrute turístico de los visitantes alojados en la costa y de los «excursionistas», pero abatido económica y socialmente. Las estrategias definidas hasta el momento para resolver tal problemática, a partir de la conservación del paisaje como acicate para incentivar el turismo, parecen ofrecer pocas expectativas a tenor lo expuesto. Dejaremos para el futuro nuevos análisis del proceso.

\section{CONCLUSIONES}

El turismo ha sido la actividad que impulsó la economía canaria hacia cotas de desarrollo jamás alcanzadas. De ser una región eminentemente rural, pasó, en tan sólo dos décadas, a sostenerse sobre las actividades terciarias de manera abrumadora, siendo el 
turismo el motor de tales cambios. El desarrollo turístico no ha sido igual ni equilibrado en todas las islas. Existe un grupo, las llamadas «islas turísticas», que absorbe abrumadoramente los beneficios y perjuicios de tal actividad, quedando otras, como La Gomera, funcionando como espacios complementarios o, en el mejor de los casos, alternativos, a esas islas principales. Su modelo turístico no difiere, a grandes rasgos, al de aquellas, pues se apoya igualmente sobre el tradicional binomio de «sol y playa», el cual ha generado una polarización territorial que se sigue dilatando en el tiempo. Frente a la concentración económica y social en tan sólo tres puntos del litoral meridional de la isla, se extiende un amplio territorio semidespoblado y sujeto a los recientes criterios de protección ambiental, paisajística y cultural que los mantiene anclados en el tiempo. Este territorio coincide con los espacios de vieja tradición rural (donde incluimos el propio Parque Nacional de Garajonay), lugares que en las últimas décadas se han ido integrando en el circuito turístico al calor de las nuevas tendencias postfordistas, fundamentalmente las derivadas de las actividades en la naturaleza y el consumo del patrimonio cultural propio de las zonas rurales. Pero, el turismo aquí no se ha consolidado como esa pluriactividad que debiera revitalizar tales espacios. Su imagen actual sigue siendo la propia de unas zonas deprimidas social y económicamente, en las que se pueden atisbar algunas pequeñas iniciativas de turismo rural que tratan de sobrevivir en un contexto francamente desfavorable, pues, estos espacios han sido marginados por un modelo turístico que únicamente los considera como lugares pintorescos que ofrecer a los turistas alojados en la costa. Por estos pueblos y ámbitos rurales transitan cada día centenares de turistas para hacer excursiones y tomar fotografías de su rico patrimonio natural y cultural, pero sin aportar nada sustancial al sostenimiento económico de sus habitantes.

Declaración responsable: Los autores declaran que no existe ningún conflicto de interés en relación a la publicación de este artículo. Las tareas se han distribuido del modo siguiente. El diseño general del artículo ha sido obra de Luis M. Jerez Darias y Víctor O. Martín Martín, así como el apartado de discusión de resultados. Las fuentes de información históricas y administrativas y las representaciones cartográficas han recaído en Luis M. Jerez Darias. La aplicación metodológica, decisiones al respecto, redacción del texto y revisión bibliográfica y Legislativa ha sido responsabilidad de ambos autores.

\section{REFERENCIAS BIBLIOGRÁFICAS}

CÁNOVES, G., HERRERA, L. y VILLARINO, M. (2005): «El turismo rural en España: paisajes y usuarios, nuevos usos y nuevas visiones», Cuadernos de Turismo, $\mathrm{n}^{\circ} 15$, pp. 63-76.

DARIAS PRÍNCIPE, A. y DÍAZ PADILLA, G. (1994): La Rada de San Sebastián de La Gomera, 1492-1992.Santa Cruz de Tenerife, Autoridad Portuaria de Santa Cruz de Tenerife.

DÍAZ HERNÁNDEZ, J.J.; LORENZO DÍAZ, D.J. y DÍAZ FARIÑA, E. (2020): Estudio del impacto económico de la crisis sanitaria del COVID-19 en Canarias. La Laguna, Universidad de La Laguna. 
DOMÍNGUEZ MÚJICA, J. (2008): «El modelo turístico de Canarias», Études Caribéennes, $\mathrm{n}^{\circ}$ 9-10, $14 \mathrm{pp}$.

ESCUELA, MÉNDEZ, R. (2016): Caracterización del visitante de un día a la isla de La Gomera: el ejemplo del jeep safari. Trabajo de Fin de Grado, Universidad de La Laguna.

EXCELTUR (2018): Impactur Canarias 2018. Estudio del Impacto Económico del Turismo.Madrid, Exceltur.

GARCÍA CABRERA, A. y CASTRO SÁNCHEZ, J.J. (2000): «Canarias y el turismo rural: tendencias, el caso de la isla de Gran Canaria», Anuario de Filosofía, Psicología y Sociología, no 3, pp. 197-222.

GARCÍA MÁRQUEZ, F. (2007): «La nueva generación de directrices territoriales y turísticas y la sostenibilidad: la experiencia canaria», Estudios Turísticos, nº 172-173, pp. 89-95.

HERNÁNDEZ LUIS, J.A., GONZÁLEZ MORALES, A., HERNÁNDEZ TORRES, S. y RAMÓN OJEDA, A. (2017): «El impacto del turismo de masas en las Islas Canarias en el contexto de las reservas mundiales de la biosfera», Cuadernos de Turismo, $\mathrm{n}^{\circ}$ 40, pp. 363-387.

JEREZ DARIAS, L.M. (2012): «La urbanización turística de Playa de Santiago: monopolización del suelo y planeamiento a la carta», Biblio $3 W, \mathrm{n}^{\circ}$ 983. Disponible en: http:// www.ub.es/geocrit/b3w-983.htm

JEREZ DARIAS, L.M. (2017): Causas y consecuencias del atraso socioeconómico de La Gomera contemporánea (1900-1980). Santa Cruz de Tenerife, Densura.

MARRERO RODRÍGUEZ, J.R. y SANTANA TURÉGANO, M.A. (2008): «Competitividad y calidad en los destinos turísticos de sol y playa. El caso de las Islas Canarias», Cuadernos de Turismo, $\mathrm{n}^{\circ}$ 22, pp. 123-143.

MARTÍN MARTÍN, V.O. (2000): El turismo en el Sur de Tenerife: de la renta agraria a la renta del ocio. Santa Cruz de Tenerife, Cabildo de Tenerife y Cabildo de Gran Canaria.

MARTÍNEZ QUINTANA, V. (2017): «El turismo de naturaleza: un producto turístico sostenible». Arbor, vol. 193 (785), 14 pp.

MORALES MATOS, G., HART, M. y CHIRIVELLA CABBALLERO, M. (1999): «Promoción e imagen del Turismo en Canarias», Boletín de la Asociación de Geógrafos Españoles, $\mathrm{n}^{\circ}$ 28, pp. 7-21.

SIMANCAS CRUZ, M. (2019): «Especulación urbanística y burbuja inmobiliaria en espacios litorales: factores explicativos del tercer boom turístico de Canarias», Cuadernos de Turismo, $\mathrm{n}^{\circ}$ 43, pp. 471-497.

PARREÑO CASTELLANO, J.M. (2008): «Turismo sostenible y diversificacion de la oferta en las islas Canarias (Espana)», Études Caribéennes, $\mathrm{n}^{\circ}$ 9-10, 19 pp.

VERA, F., LÓPEZ-PALOMEQUE, F., MARCHENA, M. y ANTON, S. (1997): Análisis territorial del turismo. Barcelona, Ariel. 